Tropical Journal of Pharmaceutical Research December 2016; 15 (12): 2549-2556

ISSN: $1596-5996$ (print); 1596-9827 (electronic)

(c) Pharmacotherapy Group, Faculty of Pharmacy, University of Benin, Benin City, 300001 Nigeria.

All rights reserved.

Available online at http://www.tjpr.org

Original Research Article

http://dx.doi.org/10.4314/tjpr.v15i12.3

\title{
Physical characterization and kinetic modelling of matrix tablets of ketorolac tromethamol formulated with polymers and waxes
}

\author{
Gülgün Yener, Evin Ayçiçek, Melike Üner* and Ebru Altuntaş \\ Department of Pharmaceutical Technology, Faculty of Pharmacy, Istanbul University, Beyazit, Istanbul 34116, Turkey
}

*For correspondence: Email: melikeuner@yahoo.com; Tel: + 90212 4400000; Fax: + 902124400252

Received: 13 May 2016

Revised accepted: 3 November 2016

\begin{abstract}
Purpose: To design controlled release ketorolac tromethamol (KT) matrix tablets for increased drug bioavailability.

Methods: Waxes (Comprito ${ }^{\circledR}$ ATO 888, Preciro ${ }^{\circledR}$ ATO 5 and stearic acid - SA) and polymers (hydroxypropyl methylcellulose - HPMC and xanthan gum - XG) were used in the preparation of the matrix tablets at various excipient concentrations for controlled drug delivery. The physical properties of the formulations were determined. Drug release profiles from the tablets were obtained and their drug release mechanisms were characterized by kinetic modeling. Analytical quantification method of KT in dissolution media was also validated by certain performance criteria.

Results: KT matrix tablets prepared individually with Compritol and HPMC at 30 and $40 \%$ concentrations, respectively, displayed the best tablet compression properties. The tablets prepared with HPMC and XG displayed slower drug release profiles compared to the tablets prepared with waxes in general $(p<0.05)$. KT release increased with increase in $p H$ since it is a weak acid $(p<0.05)$. Statistically insignificant difference was observed among all the tablets prepared with HPMC and XG in water $(p>0.05)$. However, drug release from the tablets containing $40 \% X G$ was faster than tablets prepared with HPMC (30 and $40 \%)$ and XG $(30 \%)$ at pH $7.2(p<0.05)$. Drug release mechanisms from the tablets prepared with wax and polymers were non-Fickian, indicating coupled diffusion/erosion and diffusion/polymer relaxation, respectively.

Conclusion: KT matrix tablets have been successfully formulated by direct compression method. The findings demonstrate that both the desired physical characteristics and drug release profiles were obtained for matrix tablets prepared with HPMC.
\end{abstract}

Keywords: Ketorolac tromethamol, Controlled release, Matrix tablets, Oral drug delivery, Waxes, Polymers

Tropical Journal of Pharmaceutical Research is indexed by Science Citation Index (SciSearch), Scopus, International Pharmaceutical Abstract, Chemical Abstracts, Embase, Index Copernicus, EBSCO, African Index Medicus, JournalSeek, Journal Citation Reports/Science Edition, Directory of Open Access Journals (DOAJ), African Journal Online, Bioline International, Open-J-Gate and Pharmacy Abstracts

\section{INTRODUCTION}

Ketorolac tromethamol (KT) [( \pm - - 5-benzoyl - 2, 3 - dihydro - $1 \mathrm{H}$ - pyrrolizine - 1 -carboxylic acid compound with 2 - amino - 2 - (hydroxymethyl) 1,3 - propanediol (1:1)] is a non-steroidal antiinflammatory drug (NSAID) of heterocyclic acetic acid derivatives which has a pKa of $3.54[1,2]$. It is used for short-term management of moderately severe acute and/or postoperative pain to reduce postoperative narcotic requirements. It is rapidly and completely absorbed in gastrointestinal tract. Its terminal half-life has been reported to be in the range of $5.5 \mathrm{~h}$ for healthy subjects. Peak plasma concentration occurs averagely $35 \mathrm{~min}$ after 
administration of single dose. Its recommended initial dose is $10 \mathrm{mg}$ followed by $10-30 \mathrm{mg}$ every $4-6 \mathrm{~h}$. It is prescribed for not more than 5 days for adults and as a single dose for children. Because of the risk of possible serious side effects, it is not suitable for long-term therapy $[3,4]$ related to gastrointestinal system (ulceration, bleeding and/or perforation of the stomach or intestines), vascular (cerebrovascular bleeding) and cardiovascular systems (cardiovascular thrombosis, myocardial infarction and stroke), urinary system (renal impairment).

The undesirable side effects of KT can be minimized if it is introduced in a dosage form that provides controlled drug delivery after oral administration. Matrix tablets are suitable dosage forms in this regard. When they provide sustained drug release in the gastrointestinal track, risk of systemic side effects of drugs can be minimized by administering lower daily dose to the patients. Matrix tablets also relatively easy and cost-effective to produce with high reproducibility, unlike conventional tablets for rapid drug release $[5,6]$.

The aim of this study was to design matrix tablets of KT for sustained drug release. Thus, maintaining drug in the systemic circulation for a longer time period, using a low dose may decrease the risk of side effects of KT, thus enhancing patient compliance to therapy.

\section{EXPERIMENTAL}

\section{Materials}

Ketorolac tromethamol was provided from Dr. Reddy's Laboratories Ltd. in India. Precirol ${ }^{\circledR}$ ATO 5 and Compritol 888 ATO were obtained from Gattefossé in France. Stearic acid, xanthan gum and polyvinylpyrollidone $\mathrm{K}-90$ were purchased from Cognis (Germany), CP Kelco (USA) and BASF (Germany), respectively. Methocel $\AA$ K15 Premium EP was kindly provided from Colorcon (England). Avicel® $\mathrm{PH}-102$ and magnesium stearate were obtained from Selectchemie AG (Switzerland) and Prever (Italy), respectively.

\section{Preparation of matrix tablets}

Placebo and $\mathrm{KT}$ tablets were prepared by direct compression method. KT tablets were formulated containing $40 \mathrm{mg} \mathrm{KT}$ in $180 \mathrm{mg}$ total tablet weight (Table 1). Tablets were compressed by using a biconvex punch $8.0 \mathrm{~mm}$ in diameter on a single punch tabletting machine (Korsch EK/O, Germany) under $6895 \mathrm{kp}$ compression force.

\section{Physical characterization of matrix tablets}

Carr's indexes $(\mathrm{Cl})$ and Hausner ratios $(\mathrm{HR})$ of powder mixtures were determined before compression of placebo and $\mathrm{KT}$ matrix tablets $[7,8]$.

Table 1: Composition (\%) of placebo and ketorolac tromethamol (KT) matrix tablets

\begin{tabular}{|c|c|c|c|c|c|c|c|c|c|c|c|}
\hline \multirow{2}{*}{\multicolumn{2}{|c|}{ Formulation }} & \multicolumn{10}{|c|}{ Ingredient (\%) } \\
\hline & & KT & Avicel & Compritol & Precirol & SA & HPMC & $\mathbf{X G}$ & PVP-K 90 & Aerosil & Magnesium \\
\hline \multirow{10}{*}{$\begin{array}{l}\frac{0}{0} \\
\frac{0}{0} \\
\frac{0}{0} \\
0 \\
\frac{0}{0} \\
0 \\
\frac{\pi}{0}\end{array}$} & PCo-30 & - & 63.20 & 30 & - & - & - & - & 5 & 0.8 & 1 \\
\hline & PCo-40 & - & 53.20 & 40 & - & - & - & - & 5 & 0.8 & 1 \\
\hline & PPr-30 & - & 63.20 & - & 30 & - & - & - & 5 & 0.8 & 1 \\
\hline & PPr-40 & - & 53.20 & - & 40 & - & - & - & 5 & 0.8 & 1 \\
\hline & PSA-30 & - & 63.20 & - & - & 30 & - & - & 5 & 0.8 & 1 \\
\hline & PSA-40 & - & 53.20 & - & - & 40 & - & - & 5 & 0.8 & 1 \\
\hline & PHPMC-30 & - & 63.20 & - & - & - & 30 & - & 5 & 0.8 & 1 \\
\hline & PHPMC-40 & - & 53.20 & - & - & - & 40 & - & 5 & 0.8 & 1 \\
\hline & PXG-30 & - & 63.20 & - & - & - & - & 30 & 5 & 0.8 & 1 \\
\hline & PXG-40 & - & 53.20 & - & - & - & - & 40 & 5 & 0.8 & 1 \\
\hline \multirow{10}{*}{$\begin{array}{l}\frac{0}{0} \\
\frac{0}{0} \\
\frac{ \pm}{ \pm} \\
\frac{5}{2}\end{array}$} & Co-30 & 22.22 & 40.98 & 30 & - & - & - & - & 5 & 0.8 & 1 \\
\hline & Co-40 & 22.22 & 30.98 & 40 & - & - & - & - & 5 & 0.8 & 1 \\
\hline & Pr-30 & 22.22 & 40.98 & - & 30 & - & - & - & 5 & 0.8 & 1 \\
\hline & Pr-40 & 22.22 & 30.98 & - & 40 & - & - & - & 5 & 0.8 & 1 \\
\hline & SA-30 & 22.22 & 40.98 & - & - & 30 & - & - & 5 & 0.8 & 1 \\
\hline & SA-40 & 22.22 & 30.98 & - & - & 40 & - & - & 5 & 0.8 & 1 \\
\hline & HPMC-30 & 22.22 & 40.98 & - & - & - & 30 & - & 5 & 0.8 & 1 \\
\hline & HPMC-40 & 22.22 & 30.98 & - & - & - & 40 & - & 5 & 0.8 & 1 \\
\hline & XG-30 & 22.22 & 40.98 & - & - & - & - & 30 & 5 & 0.8 & 1 \\
\hline & XG-40 & 22.22 & 30.98 & - & - & - & - & 40 & 5 & 0.8 & 1 \\
\hline
\end{tabular}

Note: Each formulation also contained PVP K90 (5 \%), Aerosil (0.8\%) and magnesium stearate (1\%) 
Bulk volume of $10 \mathrm{~g}$ of powder in a $25 \mathrm{~mL}$ measuring cylinder was recorded and the powder was then tapped 1250 times in a packed density apparatus (Erweka SVM 202, Germany) to determine packed volume. $\mathrm{Cl}$ and $\mathrm{HR}$ were calculated via bulk and packed densities [9].

Physical characterization of tablets was tested in order to determine weight variation, tablet diameter and thickness, hardness, percent friability, disintegration time [10,11]. Variations in tablet weights were determined on 20 tablets using a balance (Denver Instrument). Friability was determined by using 20 tablets in an Erweka TAR 220 friability tester (Germany) for $4 \mathrm{~min}$ at $25 \mathrm{rpm}$. Disintegration time of 6 tablets of each formulation was determined using an Erweka ZT 320 disintegrator (Germany) according to USP 32. Diameter, thickness and hardness of 10 tablets of each formulation was tested with an Erweka TBH 525 hardness tester (Germany). Tensile strength was obtained from the fracture of tablets by diametral compression $[10,12]$.

\section{Validation of analytical method for quantification of ketorolac tromethamol}

The analytical method for quantification of KT in distilled water, $\mathrm{pH} 1.2(\mathrm{HCl})$ and $\mathrm{pH} 7.2$ phosphate buffer (PB) solutions was validated and verified for linearity, intra-day and inter-day precision, accuracy, recovery and specifity by UV spectroscopy (Shimadzu UV-1700 Spectrophotometer, Japan). Each study was replicated 6 times [13].

To achieve this, UV spectra of KT were taken at each dissolution medium by scanning samples from $180 \mathrm{~nm}$ to $400 \mathrm{~nm}$ wave lengths at the absorbance mode of the apparatus. Absorption spectra of KT showed $\lambda_{\max }$ at $323 \mathrm{~nm}$ at each of the media.

\section{Linearity}

The linearity of the method was evaluated by standard linear regression analysis. 2, 4, 6, 8, 10 and $12 \mu \mathrm{g} / \mathrm{mL}$ standard $\mathrm{KT}$ solutions in dissolution media were prepared by proper dilutions of $1000 \mu \mathrm{g} / \mathrm{mL}$ stock KT solutions. Absorbance of standard solutions was measured at $323 \mathrm{~nm}$ in distilled water, $\mathrm{pH} 1.2(\mathrm{HCl})$ and $\mathrm{pH}$ 7.2 (PB) solutions. Calibration curves were constructed by plotting concentration versus absorbance using linear regression analysis.

\section{Precision, accuracy and recovery}

Intra-day and inter-day precision and the accuracy of the method were calculated from data obtained during a 2-day validation. The precision of the method was determined by intraday repeatability and inter-day intermediate precision. KT solutions in dissolution medium (2, $4,6,8,10$ and $12 \mu \mathrm{g} / \mathrm{mL}$ ) were prepared by proper dilutions of the stock KT solution (1000 $\mu \mathrm{g} / \mathrm{mL}$ ) six times on the same day. Intermediate precision was assessed by comparing the assays on different days ( 2 days, $n=3$ at each concentration).

\section{Precision}

Precision was expressed as the relative standard deviation (RSD, \%). Accuracy was expressed as the mean relative error (MRE, \%). Recovery (\%) was also calculated from the amount of drug found.

\section{Specificity}

The specificity of the method was investigated for demonstrating that the constituent in the formulations did not interfere quantification of KT. For this purpose, placebo tablets were crushed and then powdered in a mortar. $0.5 \mathrm{~g}$ powder was weighed into a $250 \mathrm{~mL}$ volumetric flask. 100 $\mathrm{mL}$ medium was added and the mixture was homogenized in an ultrasonic bath for $15 \mathrm{~min}$. The mixture was diluted to $250 \mathrm{~mL}$ with additional medium. $0.2 \mathrm{~mL}$ supernatant was withdrawn, diluted to $10 \mathrm{~mL}$ with the medium and assayed at $323 \mathrm{~nm}$. This study was repeated for each tablet series in three dissolution media.

\section{Determination of content uniformity of matrix tablets}

Tablets were powdered in a mortar. Powder containing KT equivalent to $40 \mathrm{mg}$ were taken into a $100 \mathrm{~mL}$ volumetric flask and diluted with 50 $\mathrm{mL}$ water. The suspension was kept in an ultrasonic bath for $5 \mathrm{~min}$. The suspension was filtered through a S \& S5893 blue ribbon filter paper (Schleicher und Schuell, Germany) after being diluted to $100 \mathrm{~mL}$ with additional medium. Supernatant $(2 \mathrm{~mL})$ was withdrawn and diluted properly. The final solution was assayed by UV spectroscopy. Each study was replicated 6 times. Thus, percent of KT content to the target content (40 mg) per dosage unit was calculated to determine content uniformity according to The United States Pharmacopoeia 28 and National Formulary 23 (USP 28-NF 23) [14].

\section{In vitro drug release studies}

The release of KT from tablets was studied according to the USP 32 Type II (paddle method) at $37 \pm 0.5^{\circ} \mathrm{C}$ in $900 \mathrm{~mL}$ distilled water, $\mathrm{pH} 1.2$ 
$(\mathrm{HCl})$ and $\mathrm{pH} 7.2$ (PB) solutions at $50 \mathrm{rpm}$ rotation speed by using a Varian dissolution apparatus (U.S.A.). One milliliter samples were taken by autosampling unit at predetermined time intervals and diluted to $10 \mathrm{~mL}$ and filtered through the S\&S5893 type blue ribbon filter paper. Solutions were assayed by UV spectroscopy at $323 \mathrm{~nm}$.

The kinetics of drug release from matrix tablets in three dissolution media were evaluated by zeroorder, first-order and Higuchi root-square models $[9,15]$. The dissolution data were also evaluated according to Korsmeyer-Peppas equation (exponential equation) since these models fail to explain drug release mechanism in case of swelling along with gradual erosion of the matrix due to hydration $[16,17]$. Korsmeyer-Peppas equation is often used to describe drug release behaviour from polymeric systems when the mechanism is not well-known or when more than one type of release phenomena is involved.

\section{Statistical analysis}

In vitro drug release data were evaluated using GraphPad Prism 5 software and one-way ANOVA to determine differences among release data. $P<0.05$ was set as the level of significance.

\section{RESULTS}

\section{Physical properties of matrix tablets}

Placebo tablets displayed flow and compression quality as "fair to passable" and "good" except a formulation containing $30 \%$ XG (XG-30) showed poor characteristics (Table 2). However, addition of KT altered flowability and compressibility properties of powders with very poor flow and compression quality. "Poor" or "very poor" characteristics were observed with decrease in wax or polymer concentrations in general. In the case of bulk $\mathrm{KT}$, the weakest $\mathrm{Cl}$ and $\mathrm{HR}$ values were obtained.

Tablet weights were between $176.7 \pm 0.001 \mathrm{mg}$ and $180.7 \pm 0.001 \mathrm{mg}$ for placebo tablets and, $177.2 \pm 0.001 \mathrm{mg}$ and $182.8 \pm 0.002 \mathrm{mg}$ for $\mathrm{KT}$ tablets. The lowest tensile strength (0.37 Mpa) was obtained with KT tablets (Pr-30) based on Precirol at $30 \%$ concentration. Friability values obtained were all below $0.5 \%$. Except for the tablet formulations PSA-30, PSA-40, SA-30 and $\mathrm{SA}-40$, all the tablets did not disintegrate during $10 \mathrm{~h}$ in the disintegration test performed in distilled water at $37 \pm 0.5^{\circ} \mathrm{C}$. Formulations PSA$30, \mathrm{PSA}-40, \mathrm{SA}-30$ and SA-40 disintegrated after $8,7,6$ and $6 \mathrm{~h}$, respectively.

Table 2: Compression properties of powders and physical characterization of placebo and ketorolac tromethamol (KT) matrix tablets

\begin{tabular}{|c|c|c|c|c|c|c|c|}
\hline \multicolumn{2}{|c|}{ Formulation } & \multirow{2}{*}{$\begin{array}{c}\begin{array}{c}\mathrm{Cl} \\
(\mathbf{n}=10)\end{array} \\
17.2\end{array}$} & \multirow{2}{*}{$\begin{array}{c}\text { Flow and } \\
\text { compression quality } \\
\text { Fair to passable }\end{array}$} & \multirow{2}{*}{$\begin{array}{c}\begin{array}{c}\text { HR } \\
(\mathbf{n}=10)\end{array} \\
1.20\end{array}$} & \multirow{2}{*}{$\begin{array}{c}\begin{array}{c}\text { Weight } \pm \text { SD } \\
\text { (mg) } \\
(\mathbf{n}=\mathbf{2 0})\end{array} \\
179.5 \pm 0.001\end{array}$} & \multirow{2}{*}{$\begin{array}{c}\begin{array}{c}\text { Hardness } \\
(\mathbf{N})\end{array} \\
(\mathbf{n}=\mathbf{1 0}) \\
69.0 \pm 1.47\end{array}$} & \multirow{2}{*}{$\begin{array}{r}\begin{array}{c}\text { Tensile } \\
\text { strength } \\
\text { (Mpa) }\end{array} \\
1.49\end{array}$} \\
\hline \multirow{10}{*}{$\begin{array}{l}\frac{0}{0} \\
\frac{1}{0} \\
\frac{0}{ \pm} \\
0 \\
\frac{0}{0} \\
0 \\
\frac{\pi}{0}\end{array}$} & PCo-30 & & & & & & \\
\hline & PCo-40 & 15.4 & Good & 1.18 & $179.9 \pm 0.001$ & $53.1 \pm 1.67$ & 1.10 \\
\hline & PPr-30 & 17.3 & Fair to passable & 1.21 & $180.7 \pm 0.001$ & $71.5 \pm 2.45$ & 1.48 \\
\hline & $\operatorname{PPr}-40$ & 13.3 & Good & 1.15 & $177.9 \pm 0.001$ & $64.9 \pm 2.55$ & 1.38 \\
\hline & PSA-30 & 15.1 & Good & 1.18 & $179.6 \pm 0.001$ & $96.7 \pm 1.47$ & 2.04 \\
\hline & PSA-40 & 20.5 & Fair to passable & 1.26 & $179.2 \pm 0.001$ & $93.5 \pm 1.28$ & 1.94 \\
\hline & PHPMC-30 & 18.4 & Fair to passable & 1.23 & $176.7 \pm 0.001$ & $169.0 \pm 9.22$ & 3.86 \\
\hline & PHPMC-40 & 13.8 & Good & 1.16 & $180.2 \pm 0.001$ & $146.6 \pm 0.10$ & 3.37 \\
\hline & PXG-30 & 22.2 & Poor & 1.29 & $179.3 \pm 0.001$ & $117.3 \pm 0.10$ & 2.71 \\
\hline & PXG-40 & 21.1 & Fair to passable & 1.27 & $179.0 \pm 0.001$ & $93.7 \pm 0.10$ & 2.13 \\
\hline \multirow{10}{*}{$\begin{array}{l}\frac{0}{0} \\
\frac{0}{0} \\
\frac{1}{5}\end{array}$} & Co-30 & 20.6 & Fair to passable & 1.26 & $178.9 \pm 0.003$ & $68.7 \pm 4.51$ & 1.44 \\
\hline & Co-40 & 25.5 & Fair to passable & 1.34 & $182.0 \pm 0.002$ & $68.8 \pm 3.43$ & 1.40 \\
\hline & $\operatorname{Pr}-30$ & 28.4 & Poor & 1.40 & $182.2 \pm 0.001$ & $44.6 \pm 3.73$ & 0.86 \\
\hline & $\operatorname{Pr}-40$ & 25.2 & Fair to passable & 1.34 & $177.2 \pm 0.001$ & $20.2 \pm 2.84$ & 0.37 \\
\hline & SA-30 & 30.8 & Poor & 1.45 & $179.1 \pm 0.002$ & $48.1 \pm 20.59$ & 0.92 \\
\hline & SA-40 & 33.0 & Poor & 1.49 & $179.0 \pm 0.003$ & $63.4 \pm 22.85$ & 1.31 \\
\hline & HPMC-30 & 19.3 & Fair to passable & 1.23 & $178.9 \pm 0.001$ & $61.7 \pm 4.71$ & 1.25 \\
\hline & HPMC-40 & 17.8 & Fair to passable & 1.22 & $182.8 \pm 0.002$ & $96.3 \pm 10.00$ & 1.98 \\
\hline & $X G-30$ & 32.0 & Very poor & 1.47 & $178.2 \pm 0.001$ & $66.5 \pm 5.20$ & 1.49 \\
\hline & $X G-40$ & 26.3 & Poor & 1.36 & $179.8 \pm 0.002$ & $33.4 \pm 4.41$ & 0.68 \\
\hline & Bulk KT & 36.6 & Very poor & 1.58 & - & - & - \\
\hline
\end{tabular}




\section{Validation of spectrophotometric analysis}

The representative linear equation was $A=a C+$ $b$, where $C$ is the concentration, $A$ the absorbance, $a$ is the slope, and $b$ is the intercept. In the current method, regression equations were $A=5.435 C-0.001$ with $r^{2}=0.9998$ in distilled water; $\mathrm{A}=2.544 \mathrm{C}-0.001$ with $\mathrm{r}^{2}=0.9972$ in $\mathrm{pH}$ $1.2(\mathrm{HCl})$ solution; $A=5.485 \mathrm{C}-0.001$ with $r^{2}=$ 0.9999 in $\mathrm{pH} 7.2$ (PB) solution.

R.S.D. values obtained from intra-day and interday precision of the analytical method were between $0.05-1.50 \%$ in all media. Accuracy of the method was also expressed here as MRE; lower than $2 \%$, between $0 \%$ and $1.67 \%$. Recovery of KT was between 97.25 and 100.00 $\%$. All other ingredients were found not to display absorbance at $323 \mathrm{~nm}$ which was maximum wavelength for $\mathrm{KT}$ in dissolution media indicating specificity of the method. It was demonstrated that they would not interfere quantification of KT by UV spectroscopy.

\section{Content uniformity of matrix tablets}

KT content of matrix tablets was between 38.85 $\pm 0.25 \mathrm{mg}$ and $39.96 \pm 0.08 \mathrm{mg}$. Thus, percent of
$\mathrm{KT}$ content to the target content per dosage was between $97.125 \%$ and $99.90 \%$.

\section{In vitro drug release from matrix tablets}

An insignificant difference was observed between $\mathrm{KT}$ release profiles of the matrix tablets prepared with HPMC (HPMC-30 and HPMC-40) and XG (XG-30 and XG-40) in water $(p>0.05)$. Those formulations displayed sustained drug release when matrix tablets prepared with waxes gave faster drug release $(p<0.05)$ (Fig. 1 and Table 3). On the other hand, the slowest drug release rates were obtained from matrix tablets in $\mathrm{pH} 1.2$ among the other media $(p<0.05)$. Lower than $8 \%$ of KT was released from formulations prepared with HPMC and XG at the 12th hour $(p>0.05)$ when tablets prepared with Compritol, Precirol and SA displayed higher drug release between 11.72 and $20.93 \%$ at $\mathrm{pH} 1.2(p$ $>0.05$ ). In the case of $\mathrm{pH} 7.2$ (PB) solution, the slowest drug release profile was obtained from tablets prepared with HPMC at $40 \%$ (HPMC-40) and $X G$ at $30 \%$ (XG-30) followed by formulations HPMC-30, XG-40, Co-30, Co-40, Pr-30, SA-40, Pr-40 and SA-30.

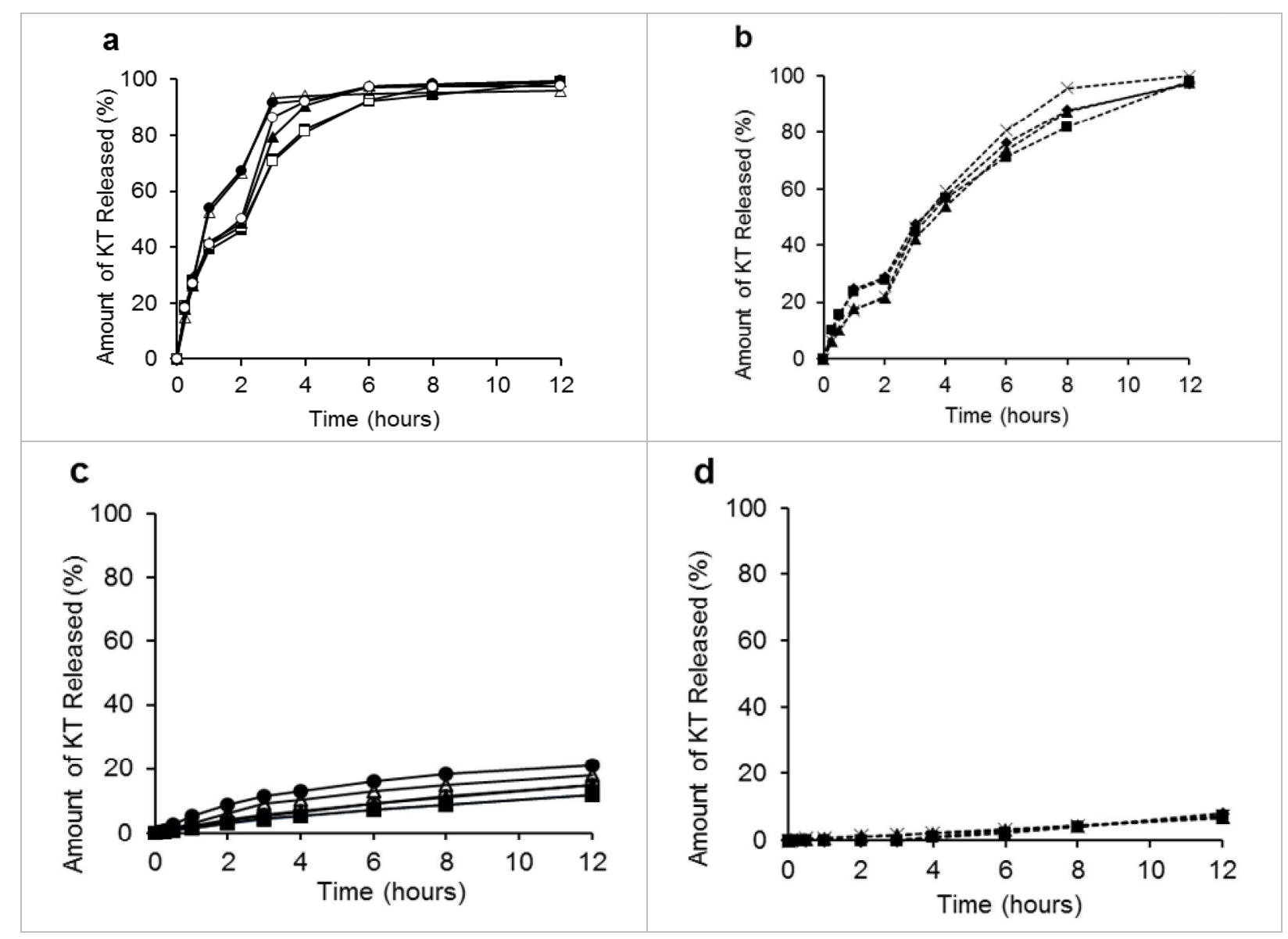



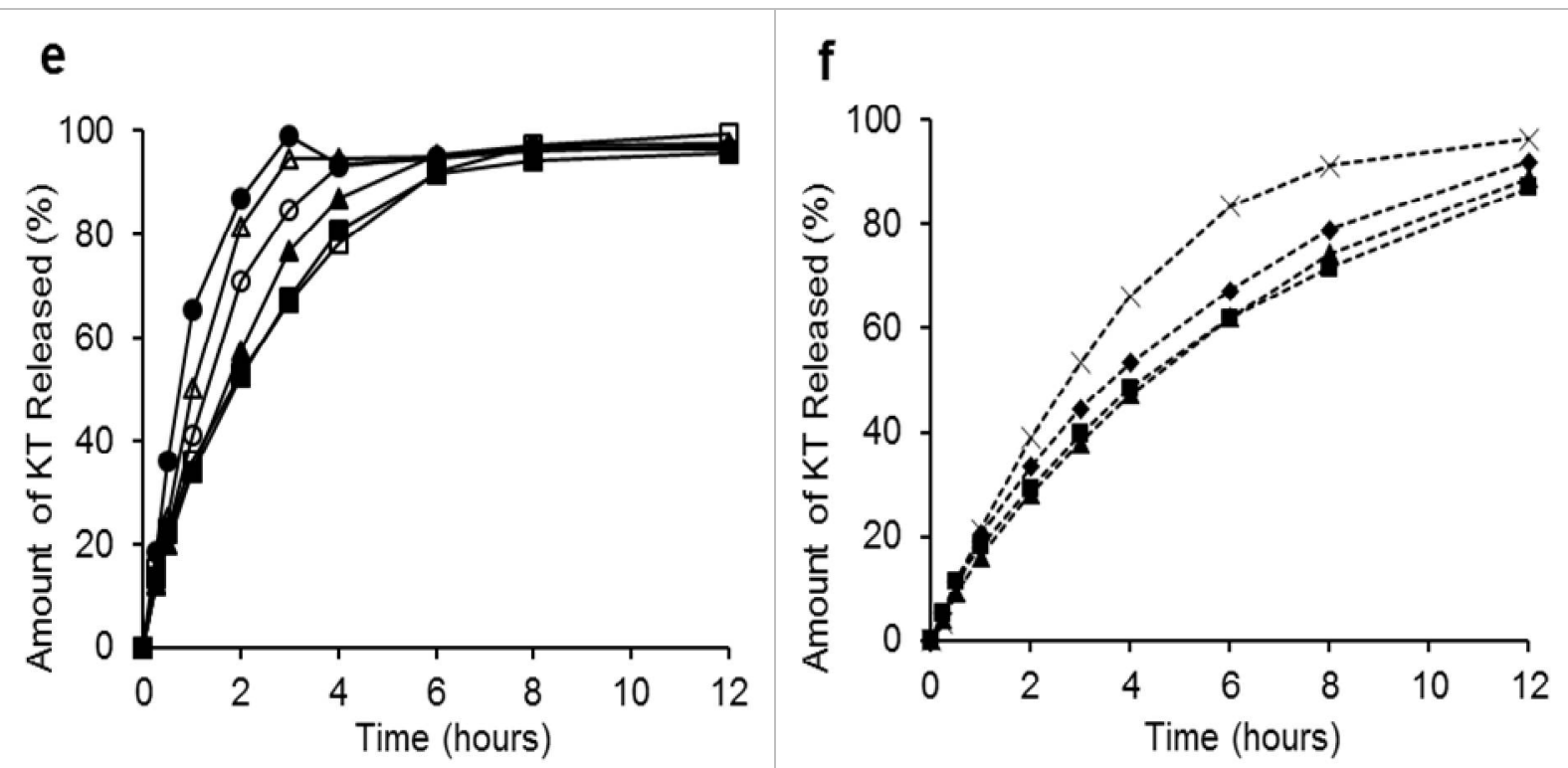

Figure 1a-f: Release profiles of KT from matrix tablets in dissolution media - distilled water (a and $\mathbf{b}), \mathrm{pH} 1.2$ $(\mathrm{HCl})\left(\mathbf{c}\right.$ and d) and $\mathrm{pH} 7.2(\mathrm{~PB})\left(\mathbf{e}\right.$ and f) solutions; , - - - = Co-30, $-\square^{-}=\mathrm{Co}-40,-\mathbf{\Delta}-=\operatorname{Pr}-30,-\Delta-=\operatorname{Pr}-40$, $-\bullet-=$ SA-30, -०- = SA-40, -- -- = HPMC-30, ----- = HPMC-40, -- $\mathbf{\Delta}--=$ XG-30, --X-- = XG-40

Table 3: Kinetic modelling of drug release from ketorolac tromethamol (KT) matrix tablets in distilled water, $\mathrm{pH}$ 1.2 and $\mathrm{pH} 7.2$, respectively

\begin{tabular}{|c|c|c|c|c|c|c|c|c|c|c|}
\hline \multirow[t]{2}{*}{ Formulation } & \multicolumn{2}{|c|}{ Zero order } & \multicolumn{2}{|c|}{ First order } & \multicolumn{2}{|c|}{ Higuchi model } & \multicolumn{2}{|c|}{$\begin{array}{l}\text { Exponential } \\
\text { (Korsmeyer - } \\
\text { Peppas model) }\end{array}$} & \multirow[t]{2}{*}{$\begin{array}{c}\text { Order of release } \\
\text { (Korsmeyer - } \\
\text { Peppas model) }\end{array}$} & \multirow[t]{2}{*}{$\begin{array}{l}\text { Diffusion } \\
\text { rate } \\
(g / h) \times 10^{3}\end{array}$} \\
\hline & $r^{2}$ & $K_{0}$ & $r^{2}$ & $K_{1}$ & $r$ & $D$ & $r^{2}$ & $n$ & & \\
\hline & 0.774 & 6.96 & 0.654 & 0.12 & 0.916 & 29.91 & 0.966 & 0.465 & Non-Fickian & 8.255 \\
\hline \multirow[t]{3}{*}{ Co-30 } & 0.979 & 0.98 & 0.722 & 0.25 & 0.991 & 3.90 & 0.995 & 0.903 & $\mathrm{n} / \mathrm{a}$ & 0.977 \\
\hline & 0.749 & 7.05 & 0.605 & 0.14 & 0.908 & 30.69 & 0.961 & 0.536 & Non-Fickian & 7.960 \\
\hline & 0.782 & 6.92 & 0.661 & 0.12 & 0.922 & 29.72 & 0.970 & 0.451 & Non-Fickian & 8.250 \\
\hline \multirow[t]{3}{*}{ Co-40 } & 0.978 & 0.97 & 0.727 & 0.23 & 0.992 & 3.86 & 0.994 & 0.844 & Non-Fickian & 0.985 \\
\hline & 0.788 & 7.25 & 0.637 & 0.13 & 0.934 & 31.19 & 0.973 & 0.517 & Non-Fickian & 8.258 \\
\hline & 0.701 & 7.01 & 0.601 & 0.12 & 0.866 & 30.79 & 0.947 & 0.479 & Non-Fickian & 8.271 \\
\hline \multirow[t]{2}{*}{ Pr-30 } & 0.984 & 1.21 & 0.102 & 0.23 & 0.989 & 4.81 & 0.998 & 0.821 & Non-Fickian & 1.235 \\
\hline & 0.692 & 7.24 & 0.559 & 0.14 & 0.869 & 32.07 & 0.941 & 0.573 & Non-Fickian & 8.129 \\
\hline \multirow{3}{*}{$\operatorname{Pr}-40$} & 0.548 & 5.97 & 0.445 & 0.11 & 0.751 & 27.61 & 0.868 & 0.471 & Non-Fickian & 7.983 \\
\hline & 0.914 & 1.49 & 0.614 & 0.24 & 0.992 & 6.13 & 0.961 & 0.912 & $\mathrm{n} / \mathrm{a}$ & 1.498 \\
\hline & 0.504 & 6.08 & 0.409 & 0.12 & 0.712 & 28.53 & 0.841 & 0.530 & Non-Fickian & 8.098 \\
\hline & 0.602 & 6.20 & 0.494 & 0.10 & 0.798 & 28.21 & 0.900 & 0.445 & Fickian & 8.292 \\
\hline \multirow[t]{3}{*}{ SA-30 } & 0.881 & 1.67 & 0.571 & 0.21 & 0.983 & 6.99 & 0.935 & 0.821 & Non-Fickian & 1.744 \\
\hline & 0.438 & 5.01 & 0.367 & 0.09 & 0.645 & 24.02 & 0.800 & 0.402 & Fickian & 8.015 \\
\hline & 0.808 & 6.77 & 0.574 & 0.12 & 0.829 & 30.15 & 0.934 & 0.473 & Non-Fickian & 8.136 \\
\hline \multirow[t]{2}{*}{ SA-40 } & 0.975 & 1.20 & 0.725 & 0.22 & 0.995 & 4.81 & 0.994 & 0.807 & Non-Fickian & 1.236 \\
\hline & 0.593 & 6.63 & 0.478 & 0.13 & 0.793 & 30.28 & 0.895 & 0.552 & Non-Fickian & 8.022 \\
\hline \multirow{3}{*}{ HPMC-30 } & 0.920 & 7.83 & 0.756 & 0.17 & 0.979 & 31.93 & 0.986 & 0.614 & Non-Fickian & 8.093 \\
\hline & 0.942 & 0.67 & 0.930 & 0.19 & 0.804 & 2.47 & 0.594 & 0.465 & Non-Fickian & 0.661 \\
\hline & 0.924 & 7.41 & 0.675 & 0.19 & 0.995 & 30.39 & 0.983 & 0.729 & Non-Fickian & 7.673 \\
\hline \multirow{3}{*}{ HPMC-40 } & 0.944 & 7.68 & 0.778 & 0.17 & 0.987 & 31.02 & 0.987 & 0.601 & Non-Fickian & 8.173 \\
\hline & 0.927 & 0.62 & 0.850 & 0.18 & 0.776 & 2.25 & 0.477 & 0.413 & Fickian & 0.611 \\
\hline & 0.942 & 6.95 & 0.698 & 0.19 & 0.998 & 28.28 & 0.986 & 0.717 & Non-Fickian & 7.260 \\
\hline \multirow{3}{*}{ XG-30 } & 0.929 & 8.42 & 0.753 & 0.09 & 0.973 & 34.04 & 0.982 & 0.755 & Non-Fickian & 8.129 \\
\hline & 0.999 & 0.54 & 0.789 & 0.27 & 0.942 & 2.09 & 0.998 & 0.951 & $\mathrm{n} / \mathrm{a}$ & 0.556 \\
\hline & 0.948 & 7.36 & 0.695 & 0.21 & 0.997 & 29.80 & 0.988 & 0.794 & Non-Fickian & 7.421 \\
\hline \multirow{3}{*}{$X G-40$} & 0.898 & 8.90 & 0.733 & 0.22 & 0.959 & 36.36 & 0.977 & 0.784 & Non-Fickian & 8.325 \\
\hline & 0.991 & 0.56 & 0.834 & 0.11 & 0.912 & 2.15 & 0.988 & 0.864 & Non-Fickian & 0.594 \\
\hline & 0.843 & 8.25 & 0.578 & 0.22 & 0.961 & 34.81 & 0.947 & 0.880 & Non-Fickian & 8.029 \\
\hline
\end{tabular}

$r^{2}$ : determination coefficient; $K_{0}$ : zero order release constant $(\mathrm{mg} \% / \mathrm{h}) ; K_{1}:$ first order release constant $\left(\mathrm{h}^{-1}\right) ; D$ : diffusion coefficient $\left(\mathrm{mg} \% / \mathrm{h}^{1 / 2}\right) ; n$ : release exponent; $n / a$ : not applicable 


\section{DISCUSSION}

Content uniformity of KT tablets were in limits (85-115\% of target content), although powders of some formulations had poor flow and compression quality. Addition of KT herewith decrease in Avicel concentration may cause that. Because, Avicel presents acceptable flow properties required for succesful large-scale tableting [18]. The physical characteristics of the placebo and KT tablets met compendial requirements, indicating homogeneous blend of ingredients and sufficient powder characteristics during the large scale compression. Tensile strength and friability of the tablets lower than 0.5 $\%$ indicated high mechanical strength of all the placebo and KT tablets. The satisfactory characteristics of the tablets can also be partially attributed to the addition of PVP-K 90, which displayed a good binding effect for formulations at $5 \%$ concentration $[18,19]$.

Validation of a quantification method is the process used to confirm that the analytical procedure employed is suitable for its intended use [13]. Before starting to study on determination of content uniformity and drug release profiles of the matrix tablets, quantification method of KT by UV spectroscopy was validated in dissolution media. The validation process demonstrated that the results attained were fit for their intended purpose and performance verification of instrumentation and equipment is concerned with ensuring that they are performing correctly.

Release profiles demonstrated a $\mathrm{pH}$-dependent mechanism of KT release from matrix tablets (Fig. 1). Since ketorolac is a weak acid with a carboxylic acid group, the influence of an acid $\mathrm{pH}$ on solubility and dissolution is the main contributing factor. Solubility of KT were reported as $0.896,0.315$ and $0.886 \mathrm{mg} / \mathrm{mL}$ in distilled water, $\mathrm{pH} 1.2(\mathrm{HCl})$ and $\mathrm{pH} 7.2(\mathrm{~PB})$ solutions, respectively [20]. Increase in $\mathrm{pH}$ resulted in an increase in $\mathrm{KT}$ release rates from all formulations

As can be seen in this study, when a system composed of hydrophylic polymers like HPMC and $X G$ gets in contact with aqueous medium, the medium difuses into the system $[16,17,21]$. Polymer at surface turns into a gel at first. When transfer of medium into the system continues, gel layer gets thicker and the system swells. In the meantime, outer gel layer continually regenerates. Drug release from KT matrix tablets fit the Higuchi kinetic model in general (Table 3). The release exponent of Korsmeyer-Peppas model (n) was taken into consideration as the parameter which is dependent on the release mechanism. Therefore, it was used to characterize drug release mechanism from matrix tablets. $\mathrm{n} \leq 0.45$ corresponds to the Fickian diffusion release (case I diffusion), $0.45 \leq$ $\mathrm{n}<0.89$ to the non-Fickian (anomalous transport), $n=0.89$ to the zero order release kinetics (case II), and $n>0.89$ to the supercase II transport in case of cylindrical matrix tablets $[16,17]$. The mechanism of drug release up to 60 $\%$ was Fickian (diffusion controlled release). The non-Fickian kinetics correspond to coupled diffusion/polymer relaxation that was clear with HPMC and XG tablets as could be expected.

In the case of waxy tablets, differences were detected only up to the 4th $\mathrm{h}$ and then, tablets displayed the same profiles. More than $90 \%$ of KT was released from tablets in distilled water and $\mathrm{pH} 7.2$ (PB) solution at about the 6th $\mathrm{h}$. The slowest release rate was observed with Compritol tablets followed by Precirol and SA. Release of KT from waxy tablets was also based on the diffusion/erosion mechanism in general.

\section{CONCLUSION}

An optimal formulation should be able to yield lower dose frequency and reduce dose-related side effects of drugs when administered orally. The matrix tablets of KT prepared with HPMC (30 or $40 \%$ ) displayed controlled drug release as well as the optimal compression properties required for large-scale production. However, further in vivo studies are required to demonstrate the effectiveness of the formulations.

\section{DECLARATIONS}

\section{Acknowledgement}

A part of this study was presented as a poster in the 8th World Meeting on Pharmaceutics, Biopharmaceutics and Pharmaceutical Technology in Istanbul/Turkey in 19 - 22 March 2012.

\section{Conflict of Interest}

No conflict of interest associated with this work.

\section{Contribution of Authors}

The authors declare that this work was done by the authors named in this article and all liabilities pertaining to claims relating to the content of this article will be borne by them.

Trop J Pharm Res, December 2016; 15(12): 2555 


\section{Open Access}

This is an Open Access article that uses a funding model which does not charge readers or their institutions for access and distributed under the terms of the Creative Commons Attribution License (http://creativecommons.org/licenses/by 14.0) and the Budapest Open Access Initiative (http://www.budapestopenaccessinitiative.org/rea d), which permit unrestricted use, distribution, and reproduction in any medium, provided the original work is properly credited.

\section{REFERENCES}

1. Martindale: The Complete Drug Reference, ed 35. London: The Pharm Pres, 2007.

2. Sinha VR, Kumar RV, Singh G. Ketorolac tromethamine formulations: an overview. Expert Opin Drug Deliv. 2009; 6(9): 961-975.

3. He A, Hersh EV. A review of intranasal ketorolac tromethamine for the short-term management of moderate to moderately severe pain that requires analgesia at the opioid level. Curr Med Res Opin 2012; 28(12): 1873-1880.

4. Singer AJ, Mynester CJ, McMahon BJ. The effect of IM ketorolac tromethamine on bleeding time: a prospective interventional controlled study. Am J Emerg Med 2003; 21(5): 441-443.

5. Honary S, Ebrahimi P, Naghibi F, Chaigani M. Controlled release formulation of indomethacin prepared with bee glue extracts. Trop J Pharm Res 2011; 10(5): 543-550.

6. Jani GK, Shah DP. Evaluation of mucilage of Hibiscus rosasinensis Linn as rate controlling matrix for sustained release of diclofenac. Drug Dev Ind Pharm 2008; 34(8): 807-816.

7. Carr RL. Evaluating flow properties of solids. Chem Eng. 1965; 72: 163-168.

8. Hausner HH. Friction conditions in a mass of metal powder. Int J Powder Metall 1967; 3(4): 7-13.

9. Üner M, Çelebi B. Design of hydralazine hydrochloride matrix tablets based on various polymers and lipids. Ind J Pharm Edu Res 2012; 46(1): 75-87.
10. Gönüllü Ü, Gürpınar $P$, Üner M. Double-layer tablets of lornoxicam: Validation of quantification method, in vitro dissolution and kinetic modelling. Trp J Pharm Res 2015; 14(9): 1659-1666.

11. Odeku OA, Fell JT. Effects of the method of preparation on the compression, mechanical, and release properties of khaya gum matrices. Pharm Dev Technol 2006; 11(4): 435-441.

12. Ramirez N, Melgoza LM, Kuentz M, Sandoval $H$, Caraballo I. Comparison of different mathematical models for the tensile strength-relative density profiles of binary tablets. Eur J Pharm Sci 2004; 22(1): 19-23.

13. ICH Harmonised Tripartite Guideline. Validation of Analytical Procedures: Text and methodology Q2 (R1) (2005).

14. The United States Pharmacopeia: USP 28: the National Formulary: NF 23: by authority of the United States Pharmacopeial Convention, Inc., meeting at Washington, DC, 2000.

15. Higuchi T. Mechanism of sustained-action medication. Theoretical analysis of rate of release of solid drugs dispersed in solid matrices. J Pharm Sci 1963; 52: 11451149.

16. Korsmeyer RW, Gurny R, Doelker E, Buri P, Peppas NA. Mechanisms of potassium chloride release from compressed, hydrophilic, polymeric matrices: effect of entrapped air. J Pharm Sci 1983; 72(10): 1189-1191.

17. Sriamornsak $P$, Thirawong $N$, Korkerd K. Swelling, erosion and release behavior of alginate-based matrix tablets. Eur J Pharm Biopharm 2007; 66(3): 435-450.

18. Rowe RC, Sheskey PJ, Owen SC. Handbook of Pharmaceutical Excipient, ed 5, revised. London and Chicago, Pharmaceutical Press, 2006.

19. Chaudhuri RK, Jaiswal DK, Haldar RK, Login RB, Tazi M, Chuang JC. Pharmaceutical tablet with pvp having an enhanced drug dissolution rate. WO 1993009763 A1, 1993.

20. Ayçiçek E. Studies on preparing and optimizing sustained release dosage forms of ketorolac trometamol and invitro release studies [dissertation]. [Istanbul]: Istanbul University; 2011.

21. Ghimire M, Hodges LA, Band J, O'Mahony B, Mclnnes $F J$, Mullen $A B$, Stevens $H N$. In-vitro and in-vivo erosion profiles of hydroxypropylmethylcellulose (HPMC) matrix tablets. J Control Release 2010; 147(1): 70-75. 